\title{
Gradient of Cosmic-Ray Intensity Perpendicular to the Elliptic Plane.
}

\author{
R. P. KANE \\ Physical Research Laboratory - Ahmedabad \\ (Nuovo Cimento, 57 B, 36 (1968))
}

In this communication a serious error has occured, viz. the dates for farthest Northern and Southern heliolatitudes have been taken as June 7 and Dec. 7 whereas these should have been March 7 and September 7 . After reanalysis, the Table II therein should read as follows:

TABLE II. - For olimax neutron monitor.

\begin{tabular}{|c|c|c|c|c|c|c|}
\hline \multirow{3}{*}{ Year } & \multicolumn{3}{|c|}{$\begin{array}{l}\text { Northern hemisphere } \\
\text { (March centring) }\end{array}$} & \multicolumn{3}{|c|}{$\begin{array}{l}\text { Southern hemisphere } \\
\text { (September centring) }\end{array}$} \\
\hline & \multirow{2}{*}{$\begin{array}{c}\text { Correlation } \\
\text { coefficient }\end{array}$} & \multicolumn{2}{|c|}{ Gradient (\%) over } & \multirow{2}{*}{$\begin{array}{l}\text { Correlation } \\
\text { coefficient }\end{array}$} & \multicolumn{2}{|c|}{ Gradient $(\%)$ over } \\
\hline & & 1/8 A.U. & 1 A. U. & & 1/8 A.U. & 1 A.U. \\
\hline 1960 & 0.18 & 0.3 & 2.5 & 0.62 & 1.1 & 8.9 \\
\hline 1961 & 0.93 & 1.8 & 14.8 & -0.89 & -2.4 & -19.4 \\
\hline 1962 & -0.81 & -0.7 & -5.2 & -0.83 & -0.7 & -5.7 \\
\hline 1963 & 0.91 & 1.7 & 13.7 & -0.29 & -0.2 & -2.0 \\
\hline 1964 & 0.15 & 0.1 & 0.6 & -0.23 & -0.2 & -1.9 \\
\hline 1965 & -0.33 & -0.3 & $-\dot{2} 2$ & -0.91 & -0.9 & -7.5 \\
\hline 1966 & 0.20 & 0.5 & 2.4 & -0.37 & -0.3 & -2.7 \\
\hline 1.967 & -0.75 & -1.1 & -8.5 & 0.05 & 0.1 & 0.5 \\
\hline 1968 & 0.24 & 0.3 & 2.6 & 0.83 & 2.0 & 16.0 \\
\hline $\begin{array}{l}\text { Average } \\
(\mathbf{1 9 6 0 - 3 8 )}\end{array}$ & 0.68 & 0.3 & 2.3 & -0.71 & -0.2 & -1.5 \\
\hline
\end{tabular}

Conelusions are roughly the same as given in the previous communication. Analysis of Deep River neutron monitor also shows similar results. 